\title{
Length of Periods in the Nasal Cycle during 24-Hours Registration
}

\author{
Atanas Todorov Atanasov \\ Department of Physics and Biophysics, Medical Faculty, Trakia University, Stara Zagora, Bulgaria \\ Email: atanastod@abv.bg
}

Received 13 May 2014; revised 12 June 2014; accepted 11 July 2014

Copyright (C) 2014 by author and Scientific Research Publishing Inc. This work is licensed under the Creative Commons Attribution International License (CC BY). http://creativecommons.org/licenses/by/4.0/

c) (i) Open Access

\begin{abstract}
The periodic congestion and decongestion of the nasal venous sinuses and an alternation of airflow from one side of the nose to the other are known in literature as "nasal cycle". It is established that nasal cycle during 24-hours registration contains from 4 to 8 time full periods, length of which varies from $0.80 \mathrm{~h}$ to $5.75 \mathrm{~h}$. The mean length of all full periods is $2.80 \pm 0.17 \mathrm{~h}$. The mean length of full periods of left nostril is $3.07 \mathrm{~h}$ and the mean length of periods of right nostril is $2.43 \mathrm{~h}$. The result suggests that there is any asymmetry in length of periods of airflow trough left and right nostrils about 40 min. The longer periods of left nostril can be connected with higher metabolic and functional activity of brain and human organism during active work.
\end{abstract}

\section{Keywords}

Nasal Cycle, Periods of Nostril, Sleep Cycle

\section{Introduction}

The spontaneous cyclical activities due to a nasal congestion and decongestion are known in literature as "nasal cycle”. Mirza et al. [1] find in the nasal cycle periods lengths ranging from approximately 1 to 5 hours during day. Gilbert [2] finds longer mean estimated period in nasal cycle during day with time-duration $4.5^{+/-1.0}$ hours (range $3.5-6.0 \mathrm{~h}$ ). Winkler et al. [3] characterized daily nasal cycle as a chaotic ultradian rhythm with a periods ranging from $1 \mathrm{~h} 15 \mathrm{~min}$ to $3 \mathrm{~h} 20$ minutes. In investigation of the nasal cycle during day Lenz et al. [5] measured a nasal cycle in $80 \%$ of 40 healthy individuals with a mean period of $2.5 \mathrm{~h}$. Atanasov et al. [5] firstly characterized nasal cycle during night sleep as ultradian rhythms with periods that multiplied to the length of sleep cycle $(1.5 \mathrm{~h})$. Atanasov and coworkers [6] showed that the switch from left to right nostril's domination airflow (and reverse) occurs only during REM phases of the night sleep. Ten years later Kimura et al. [7] received similar result. 
In conection with this we try to characterize nasal cycle during 24-hour registration, using more parameters on the time.

\section{Method, Subjects and Statistical Analyses}

The temperature difference between the inspired and expired air of each nostril was detected by two thermistors inserting in face mask. Signal of thermistors multiplies by electronic amplifier and registers by XY-recorder. The same method was used for investigation of nasal cycle during night sleep [5] [6].

Subjects were ten right-handed, healthy males (doctors), non-smoking, non-obese, non-snoring. The subjects aged-N1: 18 years, N2: 20 years, N3: 21 years, N4: 25 years, N5: 29 years, N6: 31 years, N7: 38 years, N8: 40 years, N9: 42 years and N10: 45 years. The subjects did not have a history of chronic rhinitis, none were on medications. Registration of nasal cycle was made from $7.0 \mathrm{~h}$ in the morning till $7.0 \mathrm{~h}$ of other day (morning). The assistants (general practitioner, physician, neurologist or otolaryngologist) catered apparatus and observed subjects. During the 24 hours record daily regime of subjects were the same: wake up and toilet at $6^{30}-7 \mathrm{~h}$, beginning of record $-7^{00} \mathrm{~h}$, breakfast $7^{30}-8^{00} \mathrm{~h}$, study $8^{00}-13^{00} \mathrm{~h}$, lunch and break (without sleep) $13^{00}-15^{00} \mathrm{~h}$, study $15^{00}-18^{00} \mathrm{~h}$, dinner and rest $18^{00}-22^{30} \mathrm{~h}$, toilet for sleep $22^{30}-23^{00} \mathrm{~h}$, sleep $23^{00}-7^{00} \mathrm{~h}$ (next morning).

On Figure 1(a) is shown record of airflow of left and right nostril during 24 hours period. From $7^{00} \mathrm{~h}$ to $7^{45} \mathrm{~h}$, from $11^{20} \mathrm{~h}$ to $14^{00} \mathrm{~h}$, from $16^{20} \mathrm{~h}$ to $18^{40} \mathrm{~h}$, from $24^{15} \mathrm{~h}$ to $2^{40} \mathrm{~h}$ and from $5^{15} \mathrm{~h}$ to $7^{00} \mathrm{~h}$ the airflow trough right nostril is higher versus airflow trough left nostril (i.e. right nostril dominated towards left nostril). From $7^{45} \mathrm{~h}$ to $11^{20} \mathrm{~h}$, from $14^{00} \mathrm{~h}$ to $16^{20} \mathrm{~h}$, from $18^{40} \mathrm{~h}$ to $0^{15} \mathrm{~h}$ and from $2^{40} \mathrm{~h}$ to $5^{15} \mathrm{~h}$ the airflow trough left nostril is higher versus airflow trough right nostril (i.e. left nostril dominated towards right nostril). Cyclic change of airflow of nostrils became simultaneously.

Relation of times, when dominated right nostril toward left and reverse (each nostril have higher airflow related to other) in this case was ranged as-Right: Left: Right: Left: Right: Left: Right: Left: Right $=0^{45^{\prime}} \mathrm{h}: 3^{35^{\prime}} \mathrm{h}$ : $2^{40^{\prime}}$ h: $2^{20^{\prime}}$ h: $2^{10^{\prime}}$ h: $5^{25^{\prime}}$ h: $2^{25^{\prime}}$ h: $2^{25^{\prime}}$ h: $1^{45^{\prime}}$ h.

On Figure 1(b) is shown a scheme of time periods, during which right or left nostril dominated.

The 10 records of the nasal cycle/one record of each subject/were analyzed. From the record was found 85 time periods of the nasal cycle. Insufficient periods at the beginning and at the end of each record are excluded. We analyzed just full 65 periods and present histogram of distribution of these periods according to their duration and number of observation. It is used a computing program for Windows "Statistica", for calculations.

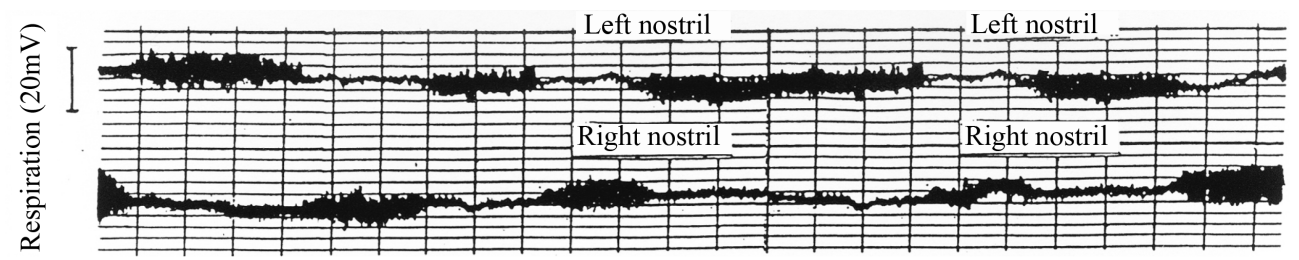

(a)

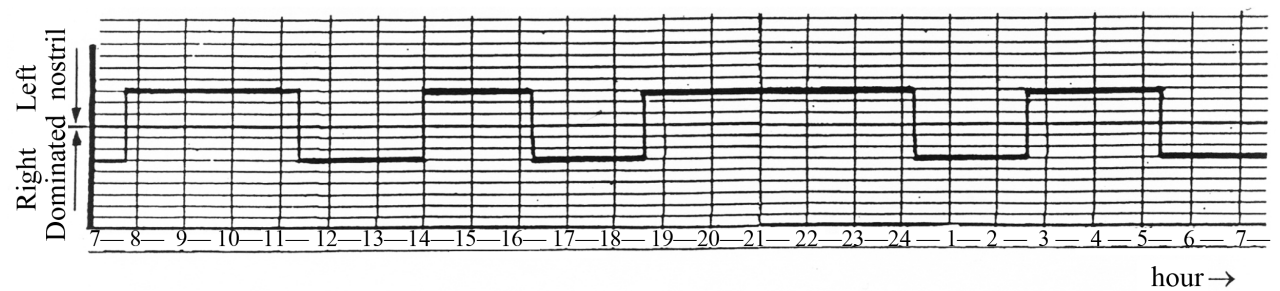

(b)

Figure 1. (a) The record of nasal cycle of left and right nostril during $24 \mathrm{~h}$ registration (from $7.0 \mathrm{~h}$ to 7.0 h of 45 years old man). The nasal cycle is of type: Right: Left: Right: Left: Right: Left: Right: Left: Right $=0^{45^{\prime}}$ h: $3^{35^{\prime}}$ h: $2^{40^{\prime}}$ h: $2^{20^{\prime}}$ h: $2^{10^{\prime}}$ h: $5^{25^{\prime}}$ h: $2^{25^{\prime}}$ h: $2^{25^{\prime}}$ h: $1^{45^{\prime}}$ h. The nasal cycle contained 8 time periods. The nostril with higher airflow has high amplitude of record. The nostril with low airflow has low amplitude of record. Temperature of room-space is $25^{\circ} \mathrm{C}$. The velocity of paper is 20 $\mathrm{mm} / \mathrm{h}$. Sensibility of scheme $4 \mathrm{mV} / 1^{\circ} \mathrm{C}$. (b) Scheme of distribution of periods of the right and left nostril. With-line are marked the duration of time-periods in the nasal cycle on record. 


\section{Results}

The lenght of full periods of the right and left nostrils varies from $0.80 \mathrm{~h}$ to $5.75 \mathrm{~h}$. The mean length of all full 65 periods of the nostrils was $\mathrm{T}=2.80 \pm 0.17 \mathrm{~h}$. The mean length of periods of left nostril was $3.07 \mathrm{~h}$ and the mean length of periods of right nostril was $2.43 \mathrm{~h}$ (see Table 1). On Figure 2 is composed histogram of distribution of all full 65 periods with approximative curve of normal (Gaussian) distribution. Values of parameters of Skewness and Kurtosis (0.28 and 1.14) are different from zero, which shows that periods haven't normal distribution. Shapiro-Wilk's W-test shows with $99.99 \%$ possibility, that distribution of periods of nasal cycle can’t be approximated by a Gaussian curve.

Mean values, standard errors of mean (SEM), 95\% confidence limits and standard deviation (SD) of all periods of left and right nostrils on histogram are given in Table 1 . The main basic maximum in distribution of periods on the histogram is about $1.75 \mathrm{~h}$. In the range around basic maximum: $0.80-2.5 \mathrm{~h}$ are $43 \%$ of all measured full periods. There are 2 secondary maximums in the distribution-about $3.25 \mathrm{~h}$ and about $4.75 \mathrm{~h}$. In the range around $3.25 \mathrm{~h}$ in interval of $2.5-3.5 \mathrm{~h}$ are $14 \%$ of all periods, and in the range around $4.75 \mathrm{~h}$ in interval 3.5 $5.75 \mathrm{~h}$ are about $30 \%$ of all periods. Registered 65 full periods of left and right nostrils during day and night time have sum duration $178.45 \mathrm{~h}(100 \%)$. Full periods only of left nostril have sum duration $98.20 \mathrm{~h}$ (55.03\% of time of all periods). Full periods only of right nostril have sum duration $80.25 \mathrm{~h}$ ( $44.97 \%$ of time of all periods).

\section{Discussion}

Registrated for $24 \mathrm{~h}$ nasal cycles contained time periods with lenght $0.80 \mathrm{~h}-5.75$ hours. The periods with similar lenght from $1 \mathrm{~h}$ to $5 \mathrm{~h}$ are more often measured in the studies of other authors during day and night [1]-[4]. The mean length of all full periods $(2.80 \mathrm{~h})$ during 24-hour registration is between mean length of periods 2.5 $3.0 \mathrm{~h}$ in the daily nasal cycle and nasal cycle during night sleep [5] [6].

The sum duration of all periods of left nostril during 24-hours registration is about $10 \%$ longer than sum duration of right nostril. For example: the mean length of all periods of left nostril ( $3.07 \mathrm{~h}$ ) is longer than mean lenght of all periods of right nostril ( $2.43 \mathrm{~h}$ ) with $0.64 \mathrm{~h}$ (38.4 min). But, the numbers of periods of two nostrils are nearly similar. The left nostril has 30 periods and right nostril has 33 periods. The result suggests, there is

Table 1. Means values, SEM, 95\% confidence limits and SD of nostril’s periods.

\begin{tabular}{ccccc}
\hline Nostrils & Means & S.E.M & 95\% confidence limits & S.D. \\
\hline Left and right & $2.80 \mathrm{~h}$ & $0.17 \mathrm{~h}$ & $2.45-3.14$ & 1.38 \\
Left nostril & $3.07 \mathrm{~h}$ & $0.26 \mathrm{~h}$ & $2.55-3.59$ & 1.45 \\
Right nostril & $2.43 \mathrm{~h}$ & $0.21 \mathrm{~h}$ & $2.00-2.87$ & 1.23 \\
\hline
\end{tabular}

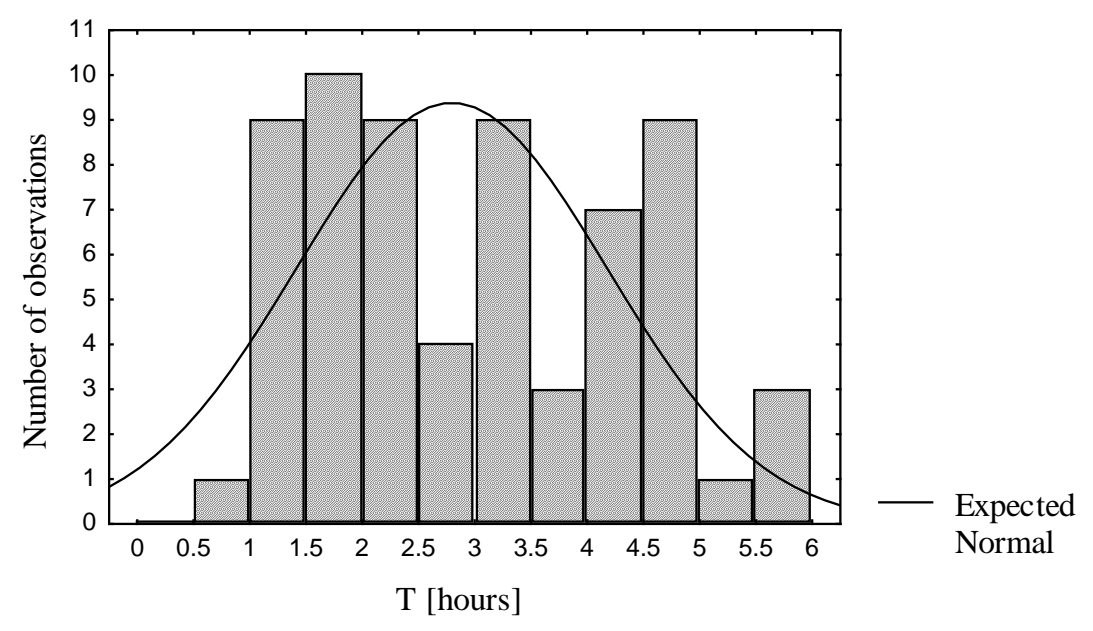

Figure 2. Histogram of number of observation and distribution of periods of the nasal cycle during $24 \mathrm{~h}$ registration ( $\mathrm{n}=65$ periods). 
any asymmetry in length of periods of the left and the right nostrils. In earlier investigations of Atanasov [8] over 120 voluntaries, a higher air-flow trough left nostril over right nostril is observed in $72 \%$ of all students during daytime. The longer length of periods of the left nostril can be connected with domination function of left hemisphere of the brain, during active work [9].

It is known, that in left hemisphere are located humane speech functions, understanding of acoustic and visual information, control of the right hand and others. Werntz et al. [10] demonsrtated by integration EEG amplitudes, that in ultradian rhythm of alternating cerebral dominance exist in humans. This rhythm is tightly coupled with the nasal cycle, since the lateralization correlates with shifts in airflow through the left and right nostrils.

\section{References}

[1] Mirza, N., Kroger, H. and Doty, R.L. (1997) Influence of Age on the "Nasal Cycle”. Laryngoscope, 107, 62-66.

[2] Gilbert, A.N. (1989) Reciprocity versus Rhythmicity in Spontaneous Alternations of Nasal Airflow. Chronobiology International, 6, 251-257. http://dx.doi.org/10.3109/07420528909056926

[3] Winkler, M., Combs, A. and Daley, C. (1994) A Chaotic Systems Analysis of the Nasal Cycle. Behaviour Science, 39, 285-292. http://dx.doi.org/10.1002/bs.3830390404

[4] Lenz, H., Theelen, W. and Eichler, J. (1985) Nasal Cycle Using Rhinomanometric Measurements (in German). Journal HNO, 33, 58-61.

[5] Atanasov, A.T., Dimov, P.D. and Dimitrov, B.D. (2003) Time Periods in the Nasal Cycle during Night Sleep. Biological Rhythm Research, 34, 355-366. http://dx.doi.org/10.1076/brhm.34.4.355.26226

[6] Atanasov, A.T. and Dimov, P.D. (2003) Nasal and Sleep Cycle-Possible Synchronization during Night Sleep. Medical Hypotheses, 61, 275-277. http://dx.doi.org/10.1016/S0306-9877(03)00169-5

[7] Kimura, A., Chiba, S., Capasso, R., Kpsgt, T.Y., Ando, Y., Watanabe, S. and Moriyama, H. (2013) Phase of Nasal Cycle during Sleep Tends to Be Associated with Sleep Stages. Laryngoscope, 123, 2050-2055. http://dx.doi.org/10.1002/lary.23986

[8] Atanasov, A.T. (1997) A Phenomenon of Dominant Nasal Air-Flow Passage trough Left Nostril in diurnal Periods. Assembled Reports of Eight National Conference "Modern tendencies in the Development of Fundamental and Applied Science”. Stara Zagora, 5-6 June 1997, 329-334.

[9] Dimond, S.J. (1980) Neuropsychology. A Textbook of Systems and Psychological Functions of the Human Brain. Butterworhs, London-Boston.

[10] Werntz, D.A., Bickford, R.G. and Shannahoff-Khalsa, D. (1987) Selective Hemispheric Stimulation by Unilateral Forced Nostril Breathing. Human Neurobiology, 6, 165-171. 
Scientific Research Publishing (SCIRP) is one of the largest Open Access journal publishers. It is currently publishing more than 200 open access, online, peer-reviewed journals covering a wide range of academic disciplines. SCIRP serves the worldwide academic communities and contributes to the progress and application of science with its publication.

Other selected journals from SCIRP are listed as below. Submit your manuscript to us via either submit@scirp.org or Online Submission Portal.
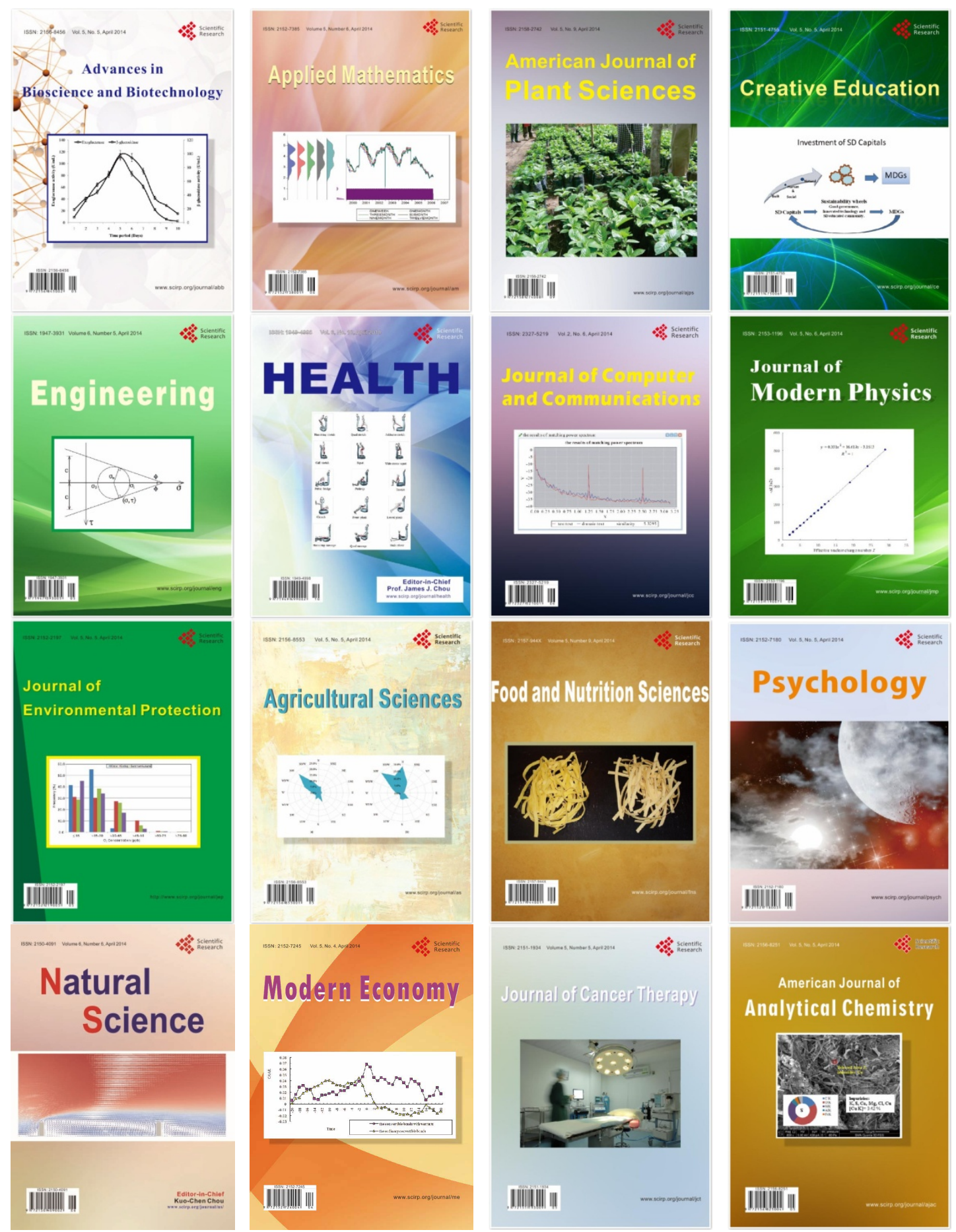